\title{
ATENCIÓN MATERNO - INFANTIL EN EL ANTIGUO PERÚ
}

\author{
Luz Marina Pilco Copaja ${ }^{1}$
}

\begin{abstract}
R E S U M E N
El médico precolombino o herbolario materno infantil tuvo una preparación muy exigente, destacándose en nuestra región sur peruana, el herbolario callawaya de origen aymara, que fue formado para preservar la defensa del bienestary salud. Dentro de esta politica de salud destaca la atencion materno infantil del binomio madre-niño.

Elembarazo y parto fueron considerados como actos naturales, esto se deduce de los secretosy consejos sobre la fecundidad vel embarazo que eran conocidos por las madres de rodos los sectores de la población prehispánica. Las enfermedades infantiles fueron plenamente identificados como se aprecia en los huacos mochicas y tiwanaku.

Dentro de la concepcion mágico-religiosa de los jampicamayoc existia la minuciosa historia clinica materno infantil donde el diagnóstico, pronóstico y curación estaban acompañadas de invocaciones de buenos augurios. El control ético y el derecho médico era ejercido dentro del ayllu que resguardaba con sanciones severas el profesionalismo de los curanderos, quienes anualmente se reunian en Sharasan donde informaban sobre las curaciones acertadas, las enfermedades extrañas atendidas, los buenos y malos resultados del empleo de las hierbas antiguas y nuevas, en suma, todo lo concerniente que habia observado, aprendido o practicado.
\end{abstract}

\section{A B S T R A C T}

The pre-colombian doctor or mother-child herbalist had a demanding preparation, being one of the most outstanding in the Southern region of Perú. The herbalist Callawaya of aymara origin, was instructed to preserve wellfare and health. Within the health policy, the mother-child attention was outstanding.

Pregnancy and birth giving were thought to be natural events, this is deduced from the secrets and advice on fertility and pregnancy known gy mothers of different areas of the pre-hispanic population. Child deseases were completely identified as shown in the Mochica's and Tiawanacu's "huacos" (ceramic pieces representing human or animal behavior).

Within the magic-religious belief of the "jampicamayoc", the meticulous mother-child health backround is found, where diagnosis, prognosis and cure came along together with promising augury. Ethics and medicine rights wew practiced in the "ayllu", which was in cherge of controlling, under strict punishement, the professionalism of quack-doctors. These people gathered every rear in Sharasan to inform about successful healings, strange deseases, the good and bad results in the use of old and nex herbs; that is to say, everything they had observed and practiced.

\section{INTRODUCCIÓN}

- El pensamiento precolombino de los nativos peruanos fue animista y mágico, guiando todos los procedimientos curativos, algunos de los cuales fueron

1. Magister en enfermeria.

con base racional experimental y constituyeron el origen del sistema cientifico que fue inherente a muchos tratamientos de las enfermedades infantiles.

Según la mitologia inca, fue "IMAY-MAMA WIRACOCHA", quien inició a los hombres en el conocimiento de la medicina. Les enseñó a diferenciar las plantas que curaban de las plantas que mataban 
y puso nombre a todos los árboles, flores y frutos; así como, a los animales.

En el antiguo Perú, consideraban que la medicina tenía intervención divina, desenvolviéndose dentro de dos aspectos: mágico-religioso y empírico-racional, representados por hechiceros y brujos, asi como por herbolarios o curanderos.

El médico brujo fue considerado hombre de poder, curaba recurriendo a ofrecimientos y sacrificios a las "huacas" y "conopas", era consultado sobre las enfermedades o desgracias y para que hablase con los dioses.

El médico andino, curandero o herbolario, era un viejo personaje en la cultura prehispánica, que en el Perú antiguo no supo distinguir la medicina cientifica de la magia y la religión; confundiéndose frecuentemente en una misma persona el médico, el brujo y el sacerdote. En aquel tiempo el "jampicamayoc o ambicamayoc", médico del Inca, representaba la sabiduria y la doctrina, traducida en el conocimiento de las creencias, supersticiones, origen de las enfermedades, la enfermedad misma y sobre los usos, costumbres, procedimientos y formas de curación.

El verdadero JAMPICUC (curandero), aparte de dar el tratamiento correspondiente, tenia la virtud de refugiarse en su paciente, convivia con él y hacia suyo el mal que lo aquejaba y se prodigaba al paciente.

En el antiguo Perú, particularmente en el Estado inca, se creia que la enfermedad era consecuencia de impureza o pecado; y el noveno mes (Coya Raymi) era dedicado a la gran purificación, en el que buscaban arrojar las enfermedades a los rios, caminos y otros, separando las enfermedades que se producian bajo determinadas condiciones climáticas de las que aparecian periódicamente y las comprendidas en una clase especial "oncok runa".

El diagnóstico se basaba en la observación y el examen físico del enfermo: tomaban el pulso en lo alto de la nariz y en la junta de las cejas.

Para los "jampicuc" de esos tiempos, todos los males tenian su correspondiente remedio, preparaban incluso, pócimas inmundas (heces humanas y orines fermentados) y cocimientos vegetales que contenían sustancias útiles para preparar purgas o purgantes, sangrías, emplastos y enemas.

Los remedios vegetales como: coca, quina, barbas del choclo, bálsamos, resinas leguminosas, cocimientos de hojas y cortezas de otras plantas eran utilizadas para curar diferentes afecciones. Las sustancias animales, como carne de vicuña, carne de cóndor, colibrí, vizcacha, sangre de zorrino, etc. eran escogidas atendiendo a razones mágicas, tenian mucha fe en las secreciones humanas, reconocian propiedades curativas en la orina, saliva y leche materna.

Por la necesidad de curar heridas y traumatismos surge la 'cirugia', practicada en reducciones de fracturas, luxaciones; amputaciones y trepanaciones craneanas con propósitos religiosos o terapéuticos, utilizando un instrumental rudimentario, como el "tumi" o gran cuchillo de metal o de obsidiana, cureta de hueso de ballena, escoplos de silex, etc.

\section{BINOMIO MADRE NIÑO PRECOLOMBINO}

Los cronistas que llegaron junto con los conquistadores españoles reconocen en sus escritos sobre el Tahuantinsuyo, que hubo una politica de seguridad social encaminada al bienestar y defensa de la salud. Los andinos precolombinos rendian culto a la madre y al niño, cuidaban de su alimentación durante el embarazo y posteriormente en la lactancia. Las madres preincas e incas prodigaban mucha ternura al niño recién nacido y eran conocedoras de la importancia capital de la leche materna, por esta razón se preocupaban de tener alimentación adecuada, a fin de asegurar un mayor periodo de lactancia para su hijo.

Pasada la primera infancia, su mayor preocupación era el cuidado del crecimiento y desarrollo del niño, evitando toda enfermedad que pudiera dañar la integridad física de sus hijos, sobre todo en caso de epidemias que atacaban las ciudades de aquella época.

Los incas evitaban la mortalidad infantil fijando zonas de maternidad y recuperación por periodos de dos a tres años, según referencias del doctor Honorio Villanueva (Archivo Histórico de Lima).

Las madres prodigaban mucho cuidado al niño y por la forma de criarlos y amamantarlos no ocasionaban alteraciones en el desarrollo de la parte inferior de la cabeza, es decir, de maxilares y dientes, pese a que en muchas zonas existian prácticas deformadoras de la cabeza. En cráneos infantiles que hoy se descubren en las zonas andinas, no se han encontrado caries dentarias, salvo algunas excepciones; el raquitismo no existía, excepto en casos aislados de desnutrición congénita. 


\subsection{EMBARAZO Y PARTO}

\subsubsection{Embarazo}

El embarazo en esa época era visto con indiferencia y las mujeres no recibian ningún control especial hasta el momento del parto, ellas tenian que soportar estoica y resignadamente todas las molestias y complicaciones propias de la gestación.

La mujer embarazada prehispánica llevaba una vida normal, caminaba grandes distancias, trepaba cerros cargando bultos y trabajaba por igual tanto en el pastoreo y labores del hogar, pareciendo que esto las hiciera más fuertes y resistentes para tener el mínimo de dolores en el parto (parto sin dolor).

En este periodo, por superstición, la gestante no deberia realizar ciertas tareas caseras como: hilar con "pushka" a fin de evitar que se formen enrollamientos alrededor del cuello y miembros del feto; sentarse con la región lumbar hacia el sol porque la placenta se podia pegar al útero y su expulsión seria dificil; no sacrificar cuyes ni matar sapos, pues el niño naceria con una enfermedad cardiaca, etc.

Los "jampicuc" aconsejaban evitar el susto para eludir el mito de los yahuas, según esto, si una mujer embarazada miraba culebras, sapos, jorobados, tullidos, etc., consideraban que podia repercutir en el hijo como una placa fotográfica. Igualmente trataban de no ver enfermos, heridos o muertos, el rayo y el arco iris, porque sus hijos podian nacer "cuyichis" (flacos, delgados o monstruosos), igual hacian con los eclipses para que los recién nacidos no tengan sombras lunares o manchas, pues la 'tinta' o 'cara' (vitiligo) eran atribuidas a estas visiones.

En estado de embarazo, una mujer no deberia cruzar un maizal con mazorcas en nacimiento y con barbas, porque podia abortar, asimismo si se bañaba en un río donde se formaba el arco iris.

Creian que los traumatismos y golpes provocaban manchas mongólico-fetales o "c'allusique", razón por la cual los varones no deberian pegar a las mujeres; las complicaciones del parto y enfermedades congénitas del niño recién nacido, eran atribuidas a hechos circunstanciales que presentaban cierta semejanza. Cuando el feto estaba en posición inconveniente, se procedía al 'arreglado' mediante la técnica de la 'cernida' o 'manteo'.

Al iniciar el trabajo de parto, la parturienta empezaba a transpirar copiosamente, los dolores se agudizaban, los 'jampicuc' aconsejaban que puje y se coloque en posición de cuclillas sobre una manta para recibir al niño. El embarazo en aquella época, estuvo rodeado de supersticiones, temores y tabúes, ya que era la llegada de un nuevo ser.

\subsubsection{Parto}

El parto fue considerado como un acto natural, en oposición a la concepción que plantea que estuvo rodeada de profundo misterio.

El nacimiento de un niño se hallaba intimamente ligado a la "Pachamama" (madretierra). Garcilaso Inca de la Vega decia: nacian sin partera y si alguien hacia este oficio era más hechicera que partera y añade .... la parida (interprétese parturienta) se regalaba, más que regalaba a su hijo porque empariendo se iba al arroyo y se lavaba y volvía hacer las haciendas de su casa como si nada hubiera pasado. Esta descripción es total y absolutamente exacta, tal como sucede actualmente con las pastoras solitarias en las lejanas punas y con las madres selváticas.

En cambio, Lucio de Castro Medina sostiene que hubieron parteras, las "huachachic" (que hacian parir); pero, por la representación de los partos en los cerámios mochicas, se deduce que la mayoria de las madres tenian un alumbramiento solas, sin ninguna clase de atención, en posición de cuclillas y cubiertas por las polleras sobre un pellejo de auquénido o una manta. Sólo en casos difíciles o partos distócicos recurrían a los "jampicuc" o "yatiris", que al mismo tiempo eran herbolarios, médicos "huachachic" equivalentes a las parteras o ginecólogos actuales.

La cultura Mochica también tiene huacos famosos, donde representan el estado de ánimo y el dolor, entre ellos algunos expresan el pujo natural en el parto, en otros se aprecia una perfecta palpación en el abdomen de una parturienta hecha por un 'clinico', con seguridad se trata de una gestante por sus senos desarrollados y porque los dos miembros inferiores se encuentran ligeramente flexionados para relajar los músculos del abdomen, conforme 
a la técnica ginecológica actual, es decir, que tenian conocimiento de la atención de la madre y el niño durante el parto. En otro huaco se puede observar la actitud obstétrica de una parturienta para dar a luz, esto es común en las madres indigenas de la sierra del Perú, 'la posición en cuclillas', asi las fuerzas expulsivas no se pierden, los partos eran normales y muy ínfimos los desgarros perineales, debido a la posición 'de sastre', que adoptaban al sentarse.

Existen también especímenes cerámicos que muestran a la "huachachic" o partera, junto a utensilios ginecológicos, sentada frente a la parturienta, extrayendo el feto magistralmente, tomando con ambas manos, justo del ángulo submaxilar inferior (se trata de un parto distósico OS). Finalmente se ve a la parturienta agotada pero tranquila, sin la expresión fisonómica de la mujer que grita de dolor en el trance del periodo expulsivo. Esto quiere decir que las madres del antiguo Perú no conocían el dolor en el parto.

El cordón umbilical lo cortaban con un cuchillo de obsidiana o bronce y se ligaban usando hilo de lana, envolviéndolo alrededor del cuello del recién nacido. El cordón placentario era ligado con cabello de la madre o lana, amarrado al dedo pulgar del pie derecho, a fin de evitar que este segmento del cordón umbilical regrese al interior del útero, esto, para facilitar la salida de la placenta. Si el recién nacido era varón la enterraban junto a los "chiuchis" (miniaturas), a fin de que sea un hombre trabajador y de bien, y si se trataba de mujer, la enterraban con objetos domésticos para que sea mujer hacendosa de su casa. Evitaban arrojar desprevenidamente la placenta, por el peligro de ser devorada por las fieras y el recién nacido sería "sua" (ladrón). En algunos lugares andinos la incineraban y esas cenizas las enterraban cerca del fogón.

En el caso de las solitarias pastoras de los mitimaes, la propia madre utilizaba otras técnicas para cortar el ombligo, tales como: chancar el cordón umbilical a prudencial distancia, golpeándolo entre dos piedras o con un instrumento cortante hecho de pedernal o con la uña; cuando la recién parida estaba acompañada, una de ellas cortaba el cordón a distinta altura: corto si era mujer y largo si era varón, con el fin que tengan vagina corta o pene largo. El pedazo de ombligo restante, cuando se desprendía entre el quinto y séptimo dia le tenian mucha estima y guardaban como medicina de sus propios niños y cuando se enfermaban se los ponian en la frente, en el pecho, en el abdomen o parte dolorida y a veces les daban en infusión o hacian chupar la tripilla - (Garcilaso).

Se practicaba la "cesárea post mórtum", cuando moría una mujer embarazada con el feto en el útero, con la finalidad de extraer el cuerpo del niño, para evitar que el espiritu del recién nacido sea arrastrado junto con su madre. Los "jampicuc" extraian el feto y la placenta, luego suturaban el útero y pared abdominal de la madre.

\subsubsection{El puerperio}

Producido el parto y retirado el niño de la madre, lo envolvian porque no acostumbraban a bañarlo inmediatamente por el frío del agua andina. En cambio, en las zonas cercanas al mar o rios tropicales, los niños eran bañados al nacer y luego arropados. A la parturienta la envolvian con una faja, "chumpi", para que no se vuelva a hinchar el vientre, produciendo la 'atonía uterina', provocando la hemorragia normal del parto. Le amarraban la cabeza con algunas hierbas como la ruda y la muña.

\subsection{SECRETOS Y CONSEJOS DE LA FECUNDIDAD Y EL EMBARAZO}

Los incas establecieron normas para la fecundidad, embarazo y parto, que eran de aplicación práctica. Dentro de ellas tenemos:

\section{a) La fecundidad}

Para que la mujer pudiera concebir la azotaban con el "guayguash" vivo, y para tener varios hijos con una "caushachic" (zarigüeya) viva o muerta.

\section{b) La infecundidad}

Se dejaba una llama o una alpaca durante algún tiempo, más o menos prolongado, en el mismo sitio, luego de ese sitio se cogía un puñado de tierra, que se le daba diluida con agua a la mujer infecunda.

Tenian la idea que las personas de carácter fuerte impresionaban vivamente a la mujer embarazada y podia transmitirla a su hijo las impresiones recibidas. Participaban de esta poderosa cualidad también los animales y las cosas.

La visión de un animal, la simple audición y 
sus gritos inarticulados bastaban para que el recién nacido tuviera grandes semejanzas con dichos animales.

Cuando la mujer estaba menstruando y miraba el arco iris, le ocasionaba dolor de vientre y podía quedar estéril.

\section{c) Embarazo}

Si la mujer gestaba un hijo, concebido en el puquio, recibían al niño en una talega y procedían a quemarlo. El hijo del puquio, según la leyenda, tiene la forma de un sapo y si lograba escapar iba directamente al ojo del puquio, introduciéndose en él para salir sólo en las noches a lactar de la madre.

Al trueno le atribuian la provocación del aborto, porque espantaba al feto y causaba la ruptura del cordón umbilical. Para evitar esta situación la madre debía llevar un amuleto, a la altura del vientre.

El trueno por el ruido producido podía determinar que el niño nazca sordo o provocar un parto prematuro.

Para el mal del embarazo, la mujer debía comer carne de buitre sancochada.

\subsection{EL ABORTO}

Según el cronista Polo de Ondegardo «Las parteras andinas no solo entendian de curar a la mujer gestante enderezando a la criatura, sino para "matalla" (hacerla morir en el cuerpo por artificios), no se sabe qué artificios, pero por el folklore sabemos que se daba "chicha hervida con ruda", la consabida "mamayupa" y otros.

También provocaban el aborto, dejándose caer desde cierta altura, propinándose golpes en el vientre, etc. y para evitar la hemorragia recurrian a infusiones astringentes como la tara, la pepa de la palta y la corteza de granada. Según Antonio Herrera, en su obra Historia de la Obstetricia en el Perú, dice que durante el incanato se protegieron a la madre y al niño: La mujer que tomaba algo para mover a la "huahua" y el "jampicuc" o hechicero que hacía de cómplice, eran desterrados a las punas más altas, condenados desde ya a la muerte.

Esto se confirma con la ley del inca Pachacútec que estimuló el crecimiento de la población, premiando con un topo de tierra al matrimonio que tuviera un hijo varón y medio topo si era mujer.

Existieron abortos voluntarios, porque no era posible aceptar que una mujer en edad de concebir sea estéril, durante el período de sus esparcimientos sexuales, cuando aún no tenia marido, y fecunda cuando lo tenia. En 1548, Polo de Ondegardo hizo esta declaración: ... los hombres y mujeres hacen otras diferentes supersticiones..., creyendo que por alli aura (hará) efecto en la generación o en la esterilidad que la pretenden, es decir, que conocían la esterilidad materna.

Entre las hierbas usadas para conseguir la esterilidad figuraban la "mallunhua" (cuscuta grandiflora). Existen referencias de que algunos pueblos usaron el sachaajo (cordia- alliodora) de origen selvático.

\subsection{LACTANCIA}

La alimentación del niño estuvo basada en la leche materna. Las mujeres andinas tenian a sus hijos colgados de los senos y la lactancia se prolongaba hasta después del año. Bernabé Cobo, cronista español, escribió: La simiente de esta hierba, quinua cocida con agua o con leche o grasa de ella aumenta la leche de la 'parida' y se han hallado por experiencia y asi lo he visto yo usar... refiriéndose a las mujeres aymaras decia: En la zona altiplánica desde épocas del Tiahuanaco, las mujeres lactantes mezclaban la quinua con el "chaco" (cal) ella dice ser buena para la salud de las madres. Esto significa que existian medios para incrementar la leche materna.

La hipogalactea era tratada tomando infusiones de quinua, maiz blanco, tarwi. Haciendo uso de las infusiones de hojas de camote, jugo de choclo tierno, etc.

\section{PEDIATRÍA}

En la época precolombina cuando se presentaban enfermedades infantiles, los pobres tenían la certeza de que éstas entraban por la "moliera" (fontanela anterior), de la misma manera que el frio, y cuidaban mucho de ella, colocándoles gorros de lana (chullos). Bañaban a sus hijos calentando el agua en su propia boca,después de vestirlos los envolvian con "chumpis" o fajas en forma de momias, con pies y manos completamente estirados desde los hombros hasta los pies, para tenerlos "quietecitos". 
Las enfermedades digestivas eran frecuentes con una mortalidad alarmante, cuando presentaban vómitos "ayascjas" o diarreas "cjaycjasjas". Las madres del incario creian que si asistian a velorios y entierros sus hijos podian morir. Asimismo, tenian terror a las enfermedades eruptivas actuales"muroonccoy", porque no se conocian remedios para su curación.

Los niños que nacian en posición podálica "chacpas" y los mellizos "tinqui huahuas" eran considerados hijos del rayo, como un castigo de Dios; en penitencia les tenian que hacer grandes sacrificios.

\subsection{ENFERMEDADES CONGÉNITAS}

Las malformaciones congénitas en los niños del incario eran pocas en cuanto a variedad, sin embargo, se presentaban con frecuencia las siguientes:

\section{LABIO LEPORINO "CAQUIO"}

Cuyo origen era atribuido a la exposición de la gestante al rayo o granizado o a que estuvo en cementerios o fue "khaikhask's" por gentiles (espiritus de los muertos).

\section{ANANCEFALEA}

Malformación del cerebro. Era atribuida a un castigo del dios Wiracocha.

\section{POLIDACTILIA}

Se atribuia a que el niño estaba poseido por los espiritus o fue "khaikhask's".

\section{"MIPA" O "YAHUA"}

Según la concepción andina, era adquirida por los niños en el vientre de su madre, debido a impresiones fuertes o asco por los animales, entonces el niño al nacer presentaba signos directos del animal (venado, perdiz, etc.). Los "yatiri" o "jampicuc" aconsejaban que las mujeres embarazadas deberian tener cuidado de no mirar personas feas, inválidas, cojas, tuertas y otros semejantes, para evitar que sus hijos nazcan con ésos defectos.

Si la gestante pasaba por un río caudaloso y turbulento, su hijo saldría 'llorón'; si veía un cadáver, el hijo nacia con la "mipa" del difunto: cejas pobladas, ojos hinchados y manchas de luto alrededor de ellos por demasiado llanto. La mipa se curaba, diagnosticando la causa, con el fin de neutralizar su influencia, haciéndola transitoria.

\subsection{ENFERMEDADES ADQUIRIDAS}

Las enfermedades adquiridas propias de la niñez, que existieron con mayor frecuencia fueron: la enterocolitis y las distrofias, donde presentaban dolor de vientre "sanconayay" y gastritis "yawar quechay".

\section{"QUECHAY" O DIARREA}

Era una consecuencia de la gastroenterocolitis causada por el frío. Cuando los niños dormian en el suelo, por comer tierra o tomar agua contaminada, presentaban dolor de estómago y cólicos. Existían también diarreas producidas por frio y calor.

Las diarreas de frío se curaban con infusiones de pepa de palta y romero hervido, o se colocaban hojitas de coca masticadas en el estómago. Cuando la diarrea era producida por el calor, la curaban con infusión del cogollo de la guayaba con maiz blanco molido y hojas de llantén, y si se trataba de un recién nacido, le daban infusiones de hojas de malva.

\section{"IRIJUA"}

Fue propia de los niños cuando la madre tenia otro hijo, a quien prodigaban mayores caños que al anterior. La manifestación era que éste se tornaba pensativo, melancólico y malhumorado, se irritaba con facilidad, lloraba y gritaba, mostrándose agresivo, perdiendo el apetito y sueño, enflaqueciendo físicamente y agotándose mentalmente. Era muy raro que la "irijua" fuera adquirida por los hijos menores, su causa se atribuia a la 'agarradura de tierra', por efecto de un maleficio, o porque la madre vio cadáveres o visitó un cementerio.

La curación se hacía mediante procedimientos mágicos de 'pagar la tierra'.

\section{SUSTO O "MANCHARISK'A"}

Enfermedad provocada por la naturaleza, consistente en la posesión del alma del niño por los espiritus malos del cerro, el agua, los animales o las "huacas".

Implicaba una pérdida temporal de la esencia vital que da la vida, movimiento y ánimo al ser humano. Esta enfermedad provocaba flujos de 
vientre, escalofrios, excesiva secreción salival y otros síntomas que alteraban sicosomáticamente al niño.

Era frecuente en los padres el temor mágico a ciertos elementos de la naturaleza: un cerro, la tempestad, un rio, la noche, etc. que causaban el 'daño del susto'. El susto se curaba haciendo volver el 'espíritu del niño' a su cuerpo, a través de prácticas mágicas. El llamado del alma fugitiva se realizaba con prendas de vestir "anmu-karkusk's". Existian varias formas de curar o quitar el sueño, así como medios de prevenir esta enfermedad. Una de ellas consistía en la confección de un poncho, utilizando dos cueros de cuy, vistiendo al niño para que no se asuste. También se colocaba en el cuello del niño un collar formado con un huairuro y maices. Sólo era posible recuperar su espiritu ofreciendo alguna ofrenda a la tierra.

\section{'MAL DE AIRE'}

Esta enfermedad se adquiria cuando un infante se exponía a la acción del 'aire malo' o viciado, que sale cuando los curanderos estaban realizando sus prácticas mágicas. Un niño con 'mal de aire' presentaba: mareos, desvanecimiento, parálisis parcial de cara, brazos, piernas, fuertes dolores musculares, dolor de oídos, garganta, etc. Se curaban con sahumerios de hierbas como: ruda, remero, retama, o friccionando el cuerpo con macerado de "amachu".

\section{'MAL DEL CUY'}

La enfermedad, según las creencias aborígenes, ocasionaba fácilmente la destrucción del ser humano. Era caracterizada por el demonio "supay", que se apoderaba del espíritu de los niños. Sus manifestaciones estaban expresadas en la mala suerte y la mala salud permanentes.

La cura se realizaba mediante actos mágicos de los curanderos.

\section{"PUQUIO ONCOOY"}

Era producido por los manantiales que emanaban gases o burbujas malolientes. A dichas emanaciones atribuian la producción de enfermedades, especialmente de los niños, tales como ostiomielitis, afecciones de la piel, trastornos de cabeza, etc.

\section{"CHIRIPA ONCCOY"}

Se conocía con este nombre a las enfermedades febriles que presentaban los niños, previos escalofríos, "chiri" o temblores "chucchos". Dentro de estas enfermedades fueron incluidas una serie de males inexplicables para los andinos.

\section{"URMACHISJA-ONCOOY"}

Enfermedad traumática, ocasionada por golpes y caídas de los niños, que producia: fracturas, luxaciones, entorsis, roturas de cabeza y otras lesiones del cuerpo.

Se curaban utilizando emplastos de arcilla, entablillados y envolturas o vendajes en la parte afectada.

\section{COLERINA}

Conjunto de trastornos hepatobiliares, que presentaban los niños, caracterizados por: dolor de estómago, cólicos, vómitos, generalmente biliares. apareció como consecuencia de peleas, contratiempos y disgustos. Se curaba con infusiones de boldo y otras hierbas frescas.

\section{PUJIDO O QUEBRADURA}

Los precolombinos consideraban que esta enfermedad se producia cuando una mujer embarazada o menstruando, 'marcaba' a un niño, resultando que el infante enfermo pujaba constantemente, como si fuera a defecar y lloraba con insistencia.

Los "yatiris" o "jampicuc", realizaban ritos mágicos para su curación.

\section{OMBLIGO SALIDO (HERNIA UMBILICAL)}

Se curaba colocando en el ombligo un ovillo de lana con un huairuro en el interior, sujetándose con una faja "chumpis".

Si se trataba de un recién nacido y el cordón umbilical no quería desprenderse, le aplicaban sebo de llama.

\section{'MAL DE OJO' (OJEO O MALOJO)}

Generalmente se presentaba en los niños que recibian la 'mirada fuerte' de un adulto. Determinada por la acción mágica que afectaba a los niños muy tiernos, los cuales presentaban escalofríos, diarreas, inapetencia, llanto e 
intranquilidad, vómitos, falta de sueño, irritabilidad, palidez, ojeras pronunciadas, pérdida de peso, etc., pudiendo llegar a morir.

Para comprobar si la guagua estaba 'ojeada' o no, los "yatiris" o médicos - brujos, realizaban procedimientos de 'limpieza con el huevo'. Esta consistía en pasar por el cuerpo del niño un huevo fresco, el que se rompia al terminar la limpieza, echándolo en un depósito con agua. Si el huevo se iba al fondo, el niño no estaba 'ojeado' y si quedaba flotando era porque tenia el 'mal del ojo' y eso bastaba para curarlo.

\section{"CHAMA" O "PATICO"}

Infección micótica que presentaba el infante en la mucosa bucal. La lengua se mostraba de color blanco, originando halitosis que coincidia con trastornos gástricos, dolor de la boca y sialorrea. En algunas oportunidades presentaba fiebre y escozor. Se curaba haciéndole enjuagatorios de infusiones de manzanilla, llantén, malva o airampo.

\section{SARNA O "SARA-ONCCOY"}

En la niñez precolombina, especialmente en las zonas rurales, alcanzó características graves, porque no se conocia un tratamiento efectivo.

Esta enfermedad, según el pensamiento andino, se presentaba cuando el niño era orinado por los sapos y zorrinos. Las consecuencias eran: enrojecimiento de la piel, sequedad y presencia de granitos en diferentes partes del cuerpo. Si el niño se rascaba podia sangrar.

Los curaban con hierbas como el matico y llantén, asi como bañándolos en aguas termales sulfurosas, abundantes en las estribaciones andinas del Perú.

\section{ESCALDADURA}

Producia enrojecimiento de la zona perinal y la presencia de pequeñas heridas que podian infectarse. Era curada utilizando hojas verdes y tostadas de taya, llantén y hierbas de toro. En algunos casos le aplicaban harina de chuño.

\section{POTROSOS}

Enfermedad caracterizada por la presencia de hernias en las ingles y ombligo. Se curaban bañándolos con hierbas e infusiones de caspilla, hierba santa, etc. procediendo luego a fajarlos.

\section{EPILEPSIA}

Producida por una gran pena, o congoja continua, que hacia morir al niño por ratos, era originada por los 'aires' desprendidos en los sitios donde viven los espíritus malos, y fue considerada propia de la niñez. Su curación se realizaba mediante acciones mágicas.

\section{PARÁLISIS FACIAL O 'AIRE'}

Afección conocida por los antiguos aborigenes, quienes lo atribuian a un 'soplo de aire frio'. Se presentaba generalmente por un cambio brusco de temperatura al salir del recinto cerrado, que tiene el calor del medio ambiente mucho más alto que del exterior. Decian 'le ha soplado el aire', se curaba con hojas de ruda fresca cuasada y paños calientes, si no se recuperaba totalmente, presentaba asimetria facial.

\section{ORZUELO}

Afección en los párpados, originada cuando el niño miraba el órgano sexual de una persona de sexo opuesto, a través de un orificio, en forma furtiva.

Se curaba lavando el ojo del enfermo con agua fria muy temprano, durante varios dias hasta que sane. Se colocaba hojas de coca caliente en la zona del 'orzuelo', o se lavaba con infusión de cola de caballo y llantén.

\subsection{ODONTOLOGÍA}

Las caries dentales eran escasas en el antiguo Perú. El andino no conocía el agente causante del dolor, asi tenemos que en excavaciones realizadas en Tacna - Perú, se han encontrado momias de niños que no presentaban caries dental.

Para curar los dolores de muelas utilizaban hierbas espinosas y amargas, animales con aspectos nauseabundos o fieras, sapos, culebras, etc., con el propósito de causar desagrado a la enfermedad que se había ubicado en los dientes y pudiera abandonarlos.

En la cultura Callawalla hubo hábiles dentistas, cuyos trabajos han dejado asombrados a los cronistas de aquella época. Esto se ha 
confirmado en los trabajos arqueológicos y hallazgos de dentaduras con coronas de oro. El trabajo de los odontólogos precolombinos se explica en relieves del cerro Sechín en CasmaPerú, cuya antigüedad data de 3500 años aproximadamente.

\section{CURACIÓN DE LOS ENFERMOS EN EL INCANATO}

Polo de Ondegardo, en la referencia de Valdizán, dice: Producida la enfermedad llamaban al brujo, variedad de jampicuc, que simultáneamente era lchuri (confesor) quien hacia una minuciosa historia clínica a la que Valdizán la llamaba "historia terapéutica", preguntando tanto por las dolencias como por las faltas cometidas, si eran niños atribuían la enfermedad a faltas de los progenitores, considerándose de una mayor gravedad: el homicidio, robo, mentira, corromper a las doncellas, incumplimiento de sus deberes con el Inca, huacas, dioses sagrados, etc. ...según la falta, se realizaba el pronóstico de la enfermedad.

En segundo lugar, se efectuaba el diagnóstico o adivinación que consistía generalmente en "chacchar coca", al mismo tiempo que le pasaban un cuy entero por todo el cuerpo del paciente o mediante otros métodos adivinatorios.

En tercer lugar, hecho el diagnóstico «adivinando el origen de la enfermedad, venian las plegarias, al dios Sol, la Luna, las estrellas y luego a los Dioses menores; Polo de Ondegardo afirma: «que sólo en el Kosko habian más de 400 de estos».

Las "huacas" más cercanas, donde muchas veces llevaban al enfermo cuando podia caminar, hacian ofrendas de chicha, charqui, perdices y otros animales, y chaquiras de oro y plata.

En cuarto lugar, se daba el arte de la curación que consistia en dar a la madre y al niño hierbas y brebajes, administradas con varios tipos de harinas mezcladas con conchas marinas finamente molidas, en muchos casos agregaban polvillos de oro, plata y la imprescindible coca.

Eran frecuentes los masajes en las partes doloridas con harina de maiz blanco y grasa de culebra, llama, etc. Las fricciones con hierbas medicinales, la succión del o de los males, mediante el cual hacian creer que chupaban la 'sangre mala' y sacaban gusanos y otras alimañas haciendo el ademán de matarlos.
Los enfermos graves se aislaban en una habitación secreta para purificarlos, quemando ramas y raices de plantas medicinales y en último instante simulaban una operación, 'extrayéndoles sapos y culebras', cuando el enfermo sanaba y estaba convaleciente y si las condiciones lo permitian, se los llevaba al puquio o río para que la corriente se llevara el mal.

Los honorarios eran siempre en comestibles, prendas y bebidas: recibían maiz, papas, ollucos, coca, buena chicha y otros. Los pacientes de mejor ubicación social y política les obsequiaban oro o plata, una llama o alpaca, vestidos, ceramios, etc.

En el transcurso de una curación, los "jampicuc" invocaban a los buenos augurios y se cuidaban de los malos para lograr curar a los enfermos.

Los más graves augurios eran la presencia de: eclipses, temblores, arco iris y otros fenómenos naturales; como sucedió con la muerte de Atahualpa, en la que se presentó un eclipse que causó pánico en los aborígenes.

\section{MEDICAMENTOS ANDINOS}

Además de las hierbas y medicinas mencionadas anteriormente, en cada una de las enfermedades, según Enrique Oblitas (cientifico boliviano), los médicos precolombinos realizaron curaciones maravillosas en poliomielitis, parálisis infantil y muchas otras enfermedades temibles, conocieron la penicilina y terramicina, aunque en forma rudimentaria. Se usó frecuentemente el plátano verde, el unto de llama, una enorme variedad de hongos con los cuales confeccionaban una serie de medicamentos para curar "heridas cancerosas crónicas y callosas». La terramicina la utilizaban en cataplasmas calientes y frías de barro fermentado.

Los médicos callawallas (tiwanakus) enviaban un gran número de herbolarios de confianza como yanaconas para cuidar a los hijos y familiares de la nobleza incaica del Cusco y otras ciudades importantes.

En la obra Magia y Medicina Popular Boliviana (La Paz, 1971) de Enrique Oblitas, menciona 106 remedios del reino animal, usados en la opoterapia callawalla, 96 drogas del reino animal, todos con sus aplicaciones en la etnia "callawalla", también aparece un listado de 546 partes del cuerpo humano y 840 enfermedades conocidas desde tiempos inmemoriales por los curanderos "callawallas". 
La terapia andina tuvo en consideración el medio ecológico, por esta razón utilizaron el traslado de los enfermos de un medio geográfico a otro.

Los "jampicuc" y herbolarios "callawallas", con el objeto de tener en secreto las hierbas que utilizaban en sus curaciones, casi nunca fueron manejadas en estado natural, sino trituradas o molidas y las llamaban "rik ich", de esta manera la gente extraña ignoraba la hierba que había sido administrada.

\section{EVALUACIÓN DE LOS HERBOLARIOS}

El control ético y el derecho médico incaico eran ejercido dentro del "ayllu" de origen de los médicos y fuera del territorio originario por la administración central incaica. El profesionalismo de los curanderos y herbolarios era resguardado por sanciones severas del "Consejo de Ancianos". Cuando se ejercia la medicina sin conocimiento de ellos, en territorios externos asignados para el ejercicio de la profesión, se castigaba drásticamente. Por ejemplo, en los "callawallas", informaban al "Consejo de Ancianos": "sobre las curaciones realizadas, las curaciones acertadas, las enfermedades extrañas atendidas, los buenos y malos resultados del empleo de las hierbas antiguas y nuevas, en suma, todo lo concerniente que habian observado, aprendido o practicado.

En las reuniones, salian a la luz nuevos métodos curativos, nuevos conocimientos y para evitar que transcendieran entre personas ajenas, estas reuniones se realizaban en secreto.

\section{BIBLIOGRAFIA}

CASTRO MEDINA, Lucio. Folklore Médico. Productos Roche, QFSA. 1981; Lima Perú.

CASTRO MEDINA, Lucio. Nuestra Comunidad Indigena Brujos y Curanderos. 1936. Lima Perú.

FRANCISCO PINEDA, David. Medicina Indígena y Popular. Libreria Editorial Juan Medina Baca. 1973. Lima Perú.

GUAMÁN POMA DE AYALA, Felipe. Primera Nueva Crónica y Buen Gobierno. Editorial Paris. 1936.

IBERICO MAS, Luis. Folklore Médico de Cajamarca, Editorial L. Moreno. Cajamarca Perú. 1988.

HINOSTROSA, Lauro. Reflexiones sobre la medicina Tradicional en elPerú. Ediciones Populares CEPCA. Lima Perú. 1988 .

KAUFFMANN DOIG, Federico. Historia General de los Peruanos Ediciones Deisa. Lima Perú. 1988.

LASTRES, Juan. Las Curaciones por las Fuerzas del Espiritu en la Medicina Incaica. Revistas Museo Nacional. Lima Perú. 1945.

LEIVA CAMPOS, Segundo. Medicina del Campo. Departamento de Acción Social. Cajamarca Perú. 1986.

LIRA, Jorge. Medicina Andina. Centro de Estudios Rurales Andinos Bartolomé de las Casas. Cuzco Perú.

OBLITAS, Enrique. Cultura Callawalla. La Paz Bolivia. 1978.

ONDEGARDO POLO. Información Acerca de la Religión y Gobierno de los Incas. Crónicas. 1581.

PAREDES, Q. Sechín Posible Centro de Conocimientos Anatómicos y de Disección en el Antiguo Perú. Cuzco Perủ. 1975.

RAVINES, Rogger. Tecnologia Andina. Institutos Peruanos. Editorial Itintec. Lima Perủ. 1978.

SEGUIN, Carlos Alberto. Psiquiatria Folklórica. Editorial Emar. Lima Perú. 1979.

VAN KESSEL, Hermilio. Medicina Andina. Cuaderno de Investigación Social Montero Impresiones SA. Iquique Chile. 1985.

VALDIZAN VERA, Luis. Cuidados a la Madre y el Niño en el Antiguo Perú. Arte Editores. Lima Perú.

VILLAVICENCIO, Victor. La Vida Sexual del Indigena Peruano. Club del Libro Peruano. Lima Perú. 1942. 